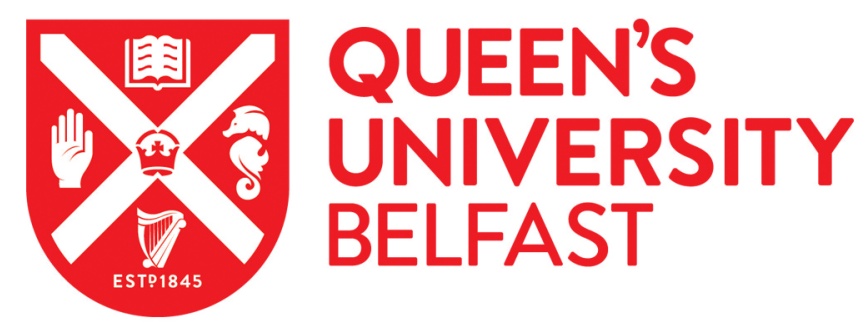

\title{
Modelling the impact of mandatory folic acid fortification of bread or flour in Ireland on the risk of occurrence of NTD-affected pregnancies in women of childbearing age and on risk of masking vitamin B12 deficiency in older adults
}

Kehoe, L., Walton, J., Hopkins, S., McNulty, B., Nugent, A. P., \& Flynn, A. (2019). Modelling the impact of mandatory folic acid fortification of bread or flour in lreland on the risk of occurrence of NTD-affected pregnancies in women of childbearing age and on risk of masking vitamin B12 deficiency in older adults. European Journal of Nutrition, 2631-2639. https://doi.org/10.1007/s00394-019-02111-4

Published in:

European Journal of Nutrition

Document Version:

Peer reviewed version

Queen's University Belfast - Research Portal:

Link to publication record in Queen's University Belfast Research Portal

Publisher rights

(C) 2019 Springer-Verlag GmbH Germany, part of Springer Nature.

This work is made available online in accordance with the publisher's policies. Please refer to any applicable terms of use of the publisher.

\section{General rights}

Copyright for the publications made accessible via the Queen's University Belfast Research Portal is retained by the author(s) and / or other copyright owners and it is a condition of accessing these publications that users recognise and abide by the legal requirements associated with these rights.

Take down policy

The Research Portal is Queen's institutional repository that provides access to Queen's research output. Every effort has been made to ensure that content in the Research Portal does not infringe any person's rights, or applicable UK laws. If you discover content in the Research Portal that you believe breaches copyright or violates any law, please contact openaccess@qub.ac.uk. 
1 Title: Modelling the impact of mandatory folic acid fortification of bread or flour in Ireland on the risk of occurrence of NTD-affected pregnancies in women of childbearing age and on risk of masking vitamin B12 deficiency in older adults.

4

5 Laura Kehoe $^{1}$, Janette Walton ${ }^{1,2}$, Sinead M Hopkins ${ }^{3}$, Breige A McNulty ${ }^{3}$, Anne P Nugent ${ }^{3,4}$ \& 6 Albert Flynn ${ }^{1}$

$7{ }^{1}$ School of Food \& Nutritional Sciences, University College Cork, Cork, Republic of Ireland;

$8 \quad{ }^{2}$ Dept. Biological Sciences, Cork Institute of Technology, Cork, Republic of Ireland;

$9 \quad{ }^{3}$ UCD Institute of Food \& Health, University College Dublin, Dublin, Republic of Ireland;

${ }^{4}$ Institute for Global Food Security, Queens University Belfast, Belfast, N. Ireland.

Corresponding author: Laura Kehoe

Room 107, School of Food and Nutritional Sciences, University College Cork, Ireland

Tel: +353 (0)21 490 3387, e-mail: laura.kehoe@ucc.ie

ORCID ID:

Laura Kehoe: 0000-0002-9030-7094

Janette Walton: 0000-0003-4758-5328

Sinead M Hopkins: N/A

Breige A McNulty: 000-0003-0841-063X

Anne P Nugent: 0000-0002-0206-1320

Albert Flynn: 0000-0002-7072-4202

Keywords: Folic acid fortification, mandatory fortification, Irish adults 
Conflicts of interest: None

26

27 Financial support: The National Adult Nutrition Survey was funded by the Irish Department of Agriculture, Food and the Marine (DAFM) under the Food for Health Research Initiative $29(2007-12)$.

30

31 Author's Contributions: AF was involved in the conception of the work and is a grant holder;

32 AF, JW, SMH, BAMcN and APN contributed to the design and execution of the study and 33 provided expert advice throughout; LK contributed to design of study, data analyses and wrote 34 the first draft. All authors contributed to the writing of the final manuscript. 


\section{Abstract}

Purpose: The rate of neural tube defects (NTDs) in Europe has remained similar since the 1990 's despite folic acid supplement recommendations $(400 \mu \mathrm{g} / \mathrm{d})$ for women of childbearing age (WBCA). Mandatory folic acid fortification of staple foods has proved effective for reducing the prevalence of NTDs in over 80 countries. This study estimated the impact of addition of folic acid to bread or flour in the Republic of Ireland on reducing the risk of occurrence of NTD-affected pregnancies and the possible risk of masking (undiagnosed) vitamin B12 deficiency in older adults.

Methods: Analyses were based on the Irish National Adult Nutrition Survey (NANS) (20082010). Folic acid fortification was modelled using DaDiet ${ }^{\complement}$ software. Estimates were made of the increase in average daily folic acid intake in women (18-50 years) and the risk of exceeding the Tolerable Upper Intake Level (UL) of $1,000 \mu \mathrm{g}$ for folic acid in adults over 50 years of age.

Results: The fortification scenarios examined would reduce the risk of NTD-affected pregnancies by $8-32 \%$, corresponding to an increase of $39-152 \mu \mathrm{g}$ in the mean daily folic acid intake of WCBA. The risk of masking anaemia associated with vitamin B12 deficiency in older adults would be negligible as the probability of exceeding the UL for folic acid, even by a small amount, is very low $(\leq 0 \cdot 2 \%)$.

Conclusions: These levels of addition of folic acid to bread or flour would effectively reduce the risk of NTDs while allowing safe consumption of folic acid at current levels from other fortified foods and supplements. 


\section{Introduction}

Neural tube defects (NTDs) including spina bifida and anencephaly result from failure of the neural tube to close during embryogenesis giving rise to serious congenital malformations of the central nervous system[1]. Ireland has long been recognised as having one of the highest rates of NTD-affected pregnancies worldwide[2]. It is well established that folic acid (the synthetic form of the B-vitamin folate) when taken prior to conception and for the first few weeks of pregnancy can prevent up to $70 \%$ of NTD-affected pregnancies[3]. Since the mid 1990's, Ireland along with many other developed countries has advised all women of childbearing age (WBCA) who are capable of becoming pregnant to consume $400 \mu \mathrm{g}$ of folic acid daily as a supplement[4-7]. However, this advice has had limited effectiveness on reducing the incidence of NTDs due to the high rate of unintended pregnancies worldwide[8] and also due to low compliance with periconceptual folic acid supplementation guidelines in WCBA[913].

Mandatory fortification of staple foods with folic acid is a feasible public health policy option for reducing the prevalence of NTDs. It can provide an advantage over supplementation and/or voluntary fortification as it is not dependent on individual choices but rather ensures a more even distribution of intake in the general population. To date, over 80 countries worldwide have legislated for the mandatory fortification of staple foods (e.g. flour or cereals) with folic acid reducing the prevalence of NTD-affected pregnancies by $16-78 \%[14-19]$. In recent years, mandatory fortification of food staples with folic acid has been under consideration in some European countries (including Ireland and the UK) but to date has not been implemented in any despite a recent study highlighting that even with long standing supplementation recommendations and the existence of voluntary folic acid fortification the prevalence of NTDs has not decreased in Europe over a twenty-year period[20,5,13,21].

Some potential risks of long-term exposure to high dose folic acid in the population have been proposed[22-27]. However, based on the available evidence, the only adverse effect for which a causal relationship with folic acid intake has been established is the possible masking of (undiagnosed) vitamin B12 deficiency anaemia in older adults, allowing the associated irreversible neurological symptoms to progress[25,28-31,24,32,33].

The potential impact of mandatory folic acid fortification of food staples has been examined through dietary modelling studies in many countries[30,34,35,28]. In Ireland, the Food Safety Authority of Ireland (FSAI) recommended the implementation of mandatory fortification of 
bread with folic acid $(120 \mu \mathrm{g} / 100 \mathrm{~g})$ in 2006[20]. However, this was subsequently postponed due to a number of factors, including a reduction in the incidence of NTDs and improved folate status of Irish population groups, likely to be due to an increased voluntary fortification of foods with folic acid[36]. In 2011, data from the nationally representative Irish National Adult Nutrition Survey (NANS) (2008-2010) showed that foods that are voluntarily fortified with folic acid made important contributions to intakes of folate in WCBA[37], yet over two-thirds of WCBA did not have optimal folate status for NTD protection $(\geq 907 \mathrm{nmol} / \mathrm{L}$ ) (median red blood cell (RBC) folate 799nmol/L)[38]. More recently there has been a significant reduction in the number of breads and fat-spreads that are voluntarily fortified with folic acid in Ireland and recent studies have suggested that the incidence of NTD-affected pregnancies may have increased from 2005-2006 to 2012-2015[20,39,40]. This has prompted renewed interest in the possibility of mandatory fortification of staple foods with folic acid to help reduce the incidence of NTD-affected pregnancies. Therefore, the aims of the current study were to estimate the impact of mandatory fortification of bread or flour with folic acid in the Republic of Ireland on first, reducing the risk of occurrence of NTD-affected pregnancies, and second, the possible risk of masking (undiagnosed) vitamin B12 deficiency in older adults.

\section{Experimental methods}

\section{Sample recruitment and food intake data collection}

Analyses for this study were based on data from the Irish National Adult Nutrition Survey (NANS), which was a cross-sectional survey conducted in the Republic of Ireland in 2008 2010 by the Irish Universities Nutrition Alliance (IUNA) units at University College Cork and University College Dublin to establish a database of habitual food and beverage consumption in a representative sample of 1500 adults aged between 18 and 90 years (men: $n=760$; women: $n=740$ ). A detailed overview on sampling and recruitment, food intake data collection and food quantification methods are outlined elsewhere[41,42,38,43]. The study was conducted according to the guidelines laid down in the Declaration of Helsinki and ethical approval was obtained from the Clinical Research Ethics Committee of the Cork Teaching Hospitals, University College Cork [ECM 3 (p) 4 September 2008] and informed consent was obtained from all participants. Food and beverage intake data were collected using a 4-day semi-weighed food record as described in detail elsewhere[41,42,38,43]. For all participants, the study period included at least one weekend day. The final response rate for the survey was $60 \%$ (response rate calculated as: number of participants / (total contacted - ineligible) X100). Demographic 
analysis of the sample has shown it to be nationally representative of Irish adults with respect to age, gender, social class and geographical location when compared to Irish Census 2006 data[44].

\section{Estimation of folate and folic acid intake at baseline}

Total folate intake was estimated using data from McCance and Widdowson's The Composition of Foods, fifth and sixth editions plus all nine supplemental volumes as described elsewhere[41]. This dataset was updated to include recipes of composite dishes, nutritional supplements, fortified foods and generic Irish foods that were commonly consumed and new foods on the market[45]. To estimate folic acid intake, fortified foods and nutritional supplements containing folic acid were identified using the ingredients list on the label at the time of the survey. The folic acid composition of fortified foods and nutritional supplements was established from the food packaging labels or obtained directly from the manufacturer. The majority of manufacturers reported that the folate value on the nutrition label corresponded to the amount of total folate in the product (i.e. natural folate and added folic acid combined). The added folic acid content of fortified foods was therefore estimated as the difference between total folate content as declared on the label (where appropriate) and the natural folate content obtained from manufacturers or published food composition data for an unfortified equivalent. Due to the significant reduction in the number of breads and fat spreads voluntarily fortified with folic acid since the time of the survey (2008-2010), the food composition database was further updated in 2015 for these food categories. Dietary folate equivalents (DFE) were estimated using the following equation: $1 \mu \mathrm{g} \mathrm{DFE}=1 \mu \mathrm{g}$ food folate $+\left(1.7^{*}\right.$ Folic Acid)[46]. As it is usual for manufacturers to include additional amounts of nutrients as 'overage' in fortified foods and supplements to allow for losses during processing and shelf life, all estimates of folic acid intakes factored in an overage of $25 \%$ compared to that declared on the label for voluntarily fortified foods and nutritional supplements. Seven individuals consuming supplements which contained levels of folic acid deemed to be medicinal $(5000 \mu \mathrm{g})$ were removed from the analysis.

\section{Modelling scenarios}

The modelling scenarios were conducted using DaDiet $\odot$ (Version 15.05; Dazult Ltd, Co. Kildare, Republic of Ireland). The models included addition of folic acid to: 
1) Selected breads at a level of $120 \mu \mathrm{g} / 100 \mathrm{~g}$ bread, as consumed, as recommended by the Irish National Committee on Folic Acid Food Fortification[20].

2) Selected breads at a level of $225 \mu \mathrm{g} / 100 \mathrm{~g}$ bread, as consumed, equivalent to the level of addition to flour recommended by the UK Scientific Advisory Committee on Nutrition[5].

3) All wheat flour at a level of $225 \mu \mathrm{g} / 100 \mathrm{~g}$, as consumed as recommended by the UK Scientific Advisory Committee on Nutrition[5].

Further details on these scenarios are provided below:

\section{Addition of folic acid to bread}

For both bread models, all food codes relating to white, wholemeal and brown pan-breads and rolls and recipes containing white or brown bread in which the weight of bread contributed $>10 \%$ of the total recipe weight were identified for inclusion. (Breads excluded from the models were: white and brown soda breads, gluten free breads, pitta breads, scones, bagels, croissants, paninis, tortillas, bracks, currant breads, muffins, malt and rye breads and naan breads). The amount of folic acid from mandatory fortification was calculated as follows:

Folic acid intake $(\mu \mathrm{g})=120 \mu \mathrm{g}$ folic acid / $100 \mathrm{~g}$ x weight of bread consumed $(\mathrm{g})$

Folic acid intake $(\mu \mathrm{g})=225 \mu \mathrm{g}$ folic acid $/ 100 \mathrm{~g} \times$ weight of bread consumed $(\mathrm{g})$

For recipes, the proportion of the total weight made up by bread was estimated and the folic acid content for that proportion was calculated as per the above formula. Folic acid in breads that are currently fortified with folic acid voluntarily was removed (changed to $0 \mu \mathrm{g}$ ) for the bread models.

\section{Addition of folic acid to flour}

For flour, food groups which were contributors to wheat flour in the diet were identified and included breads, biscuits, savouries, cakes, pastries, buns, sponge and other cereal-based puddings. The amount of wheat flour per $100 \mathrm{~g}$ of each food was estimated from the starch content of the food based on the assumption that all the starch content came from flour and that $1 \mathrm{~g}$ of flour contains $0.762 \mathrm{~g}$ of starch[47]. The amount of flour was calculated for each food as follows:

Flour content $(\mathrm{g})=$ starch content $(\mathrm{g}) / 0.762$ 
The amount of folic acid from mandatory fortification was calculated for each food as follows: Folic acid intake $(\mu \mathrm{g})=225 \mu \mathrm{g} / 100 \mathrm{~g} \mathrm{x}$ weight of flour consumed $(\mathrm{g})$

Folic acid in flour-containing foods that are currently fortified with folic acid voluntarily was removed (changed to $0 \mu \mathrm{g}$ ) for the flour model.

Four scenarios were created and assessed for all bread and flour models (Table 1)

A) Intakes of folic acid were examined from mandatory fortification of bread or flour including folic acid intake at current levels from voluntarily fortified foods and nutritional supplements.

B) Intakes of folic acid were examined from mandatory fortification of bread or flour and included folic acid intake at current levels from nutritional supplements but excluding folic acid from voluntarily fortified foods.

C) Intakes of folic acid were examined from mandatory fortification of bread or flour and included folic acid intake at current levels from voluntarily fortified foods but excluding folic acid from nutritional supplement use.

D) Intakes of folic acid were examined from mandatory fortification of bread or flour only excluding all other sources of folic acid.

\section{Estimation of usual intakes}

Usual intake distributions of folic acid were estimated using the validated National Cancer Institute (NCI)-Method[48] using SAS Enterprise Guide(C) Version 6.1 (SAS Institute Inc., Cary, NC, USA). The NCI-method has been implemented in SAS macros (version 2.1) which were downloaded from the website www.riskfactor.gov/diet/usualintakes/macro.html (date of download: July 2015). The NCI-method calculates usual intake based on non-linear mixed regression models. The model separates usual intake into two parts: the probability to consume a food or nutrient on a particular day, and given that the food/nutrient was consumed, the amount eaten on the consumption day. In addition to the correction for within-person errors in the dietary data, the statistical model includes a random effect to account for person-specific errors. This method results in a better estimate of the true distribution of usual intakes of nutrients with shorter tails at the upper and lower ends therefore improving the estimates of the proportions of the population with intakes above or below a particular reference value (e.g. EAR or UL) which would otherwise be overestimated. 
Estimates were made of the reduction in risk of occurrence of NTD-affected pregnancies based on the increase in average daily folic acid intake from fortified bread or flour in women aged 18 - 50 years ( $n$ 485). The studies of Daly et al[49] and Daly et al[50] were used to relate the additional intake of folic acid to the reduction in risk of NTDs (established through a continuous relationship with maternal RBC folate levels). Based on the observations provided by Daly et al for $100 \mu \mathrm{g}$ and $200 \mu \mathrm{g}$ supplements of folic acid, an additional intake of $100 \mu \mathrm{g}$ folic acid corresponds to a reduction in risk of NTDs of $22 \%$ and an additional intake of 101 $200 \mu \mathrm{g}$ folic acid corresponds to a further reduction in risk of NTDs of $19 \%$.

Assessing the possible risk of masking anaemia associated with (undiagnosed) vitamin B12

\section{deficiency in older adults}

The possible risk of masking of megalobalstic anaemia associated with (undiagnosed) vitamin B12 deficiency in older adults was assessed from the probability of exceeding the Tolerable Upper Intake Level (UL) of $1000 \mu \mathrm{g}$ for folic acid[51] based on the total intake of folic acid in men and women aged over 50 years ( $n 527$ ), together with the magnitude of any possible excess above the UL. For each fortification scenario the increase in the $\%>$ UL and the 95th and 99th percentile of folic acid intake were calculated for adults aged $>50$ years. In addition, intakes of folic acid in the highest consumers were examined to estimate the magnitude of any possible excess above the UL.

\section{Results}

\section{Usual distribution of folate intakes at baseline}

230

The distribution of usual intakes of total folate, natural folate, folic acid and dietary folate equivalents (DFE) in women of child bearing age (WCBA) $(18-50$ years) and older adults ( $>50$ years) at baseline is presented in Table 2. Mean dietary intakes of total folate, natural folate, folic acid and DFE were 308, 195, 114 and $385 \mu \mathrm{g} / \mathrm{d}$, respectively, in WBCA and 347, 237,111 and $421 \mu \mathrm{g} / \mathrm{d}$, respectively, in older adults. Overall $74 \%$ of WCBA consumed folic acid from voluntarily fortified foods $(70 \%)$ or nutritional supplements $(16 \%)$ with a mean intake of 63 and $51 \mu \mathrm{g} / \mathrm{d}$, respectively. Foods voluntarily fortified with folic acid consumed in the NANS are presented in Supplementary Table 1. For older adults, 66\% consumed folic acid from voluntarily fortified foods $(61 \%$; mean $72 \mu \mathrm{g} / \mathrm{d})$ or nutritional supplements $(13 \%$; 
mean $40 \mu \mathrm{g} / \mathrm{d})$. The 95 th percentile intake of total folic acid was 427 and $409 \mu \mathrm{g} / \mathrm{d}$ for WCBA and older adults, respectively.

Impact of mandatory folic acid fortification of bread or flour on usual folic acid intakes in women of childbearing age (WCBA)

The impact of mandatory fortification of bread or flour on folic acid intakes and reduction in NTD risk in WCBA is presented in Table 3. At baseline, 74\% of WCBA consumed folic acid from voluntarily fortified foods and/or nutritional supplements (mean intake; $114 \mu \mathrm{g} / \mathrm{d}$ ). All scenarios involving the mandatory folic acid fortification of bread or flour would increase the proportion of WCBA consuming folic acid to 90 - 99\% with the greatest increase observed for the bread models 120A and 120C (96\%), 225A and 225C (96\%) and all flour models (99\%). For the bread 120A-D models, the greatest effect on mean intake of folic acid in WCBA would be observed for bread120A resulting in an increase of $77 \mu \mathrm{g} / \mathrm{d}$, equivalent to a reduction in risk of NTD-affected pregnancies by $17 \%$. The exclusion of folic acid from voluntarily fortified foods or nutritional supplements (Bread120B-C models) would result in smaller reduction in risk of NTD-affected pregnancies ( 3 to $6 \%$ ) while exclusion of folic acid from both voluntarily fortified foods and nutritional supplements (Bread120D) would result in increased risk of NTD-affected pregnancies (7\%) highlighting the important contribution of currently voluntarily fortified foods and supplements to folic acid intake in this population group. For the bread225 and flour225 models examined, bread225A and flour225A would reduce the risk of NTD-affected pregnancies by 31 and 32\%, respectively, equivalent to an increase of 148 and $152 \mu \mathrm{g}$ folic acid/d in WCBA. For both bread225 and flour225 models, exclusion of folic acid from voluntarily fortified foods, nutritional supplements or both would result in smaller reductions in risk of NTD-affected pregnancies $(19,21$ and 8\%, respectively for Bread225BD) and (20, 22 and 9\%, respectively for Flour225B-D).

Impact of mandatory folic acid fortification of bread or flour on usual folic acid intakes in older adults (>50 years)

The impact of mandatory fortification of bread or flour on folic acid intakes and the proportion of older adults with intakes greater than the UL is presented in Table 4. At baseline, $66 \%$ of older adults consumed folic acid from voluntarily fortified foods and/or nutritional supplements (mean intake; $111 \mu \mathrm{g} / \mathrm{d}$ ) with $0.1 \%$ having intakes above the UL. All modelling scenarios would increase the number older adults consuming folic acid to $92-100 \%$. However, for all scenarios the probability of exceeding the UL for folic acid, even by a small amount is 
very low $(\leq 0.2 \%)$. The magnitude of any possible excess intake of folic acid above the UL would be small, given the patterns of folic acid intake observed in the highest consumers. P95 and P99 intakes of folic acid did not exceed 623 or $822 \mu \mathrm{g} / \mathrm{d}$, respectively, for any fortification scenario examined. The highest consumption of folic acid in these fortification scenarios was mainly associated with use of multiple supplements and supplements containing $400 \mu \mathrm{g}$ folic acid per daily amount. Thus, the risk of masking anaemia associated with (undiagnosed) vitamin B12 deficiency would be negligible.

\section{Discussion}

This study examines the potential impact of mandatory folic acid fortification of bread or flour in the Republic of Ireland on reducing the risk of occurrence of NTD-affected pregnancies in WCBA and also on the possible risk of masking (undiagnosed) vitamin B12 deficiency anaemia in older adults. The main finding was that the levels of addition of folic acid to bread or flour examined in this study would significantly reduce the risk of NTD-affected pregnancies while allowing safe consumption of folic acid for older adults at current levels of intake from other foods voluntarily fortified with folic acid and from nutritional supplements.

Of the scenarios examined in this study the mandatory fortification of bread or flour with $225 \mu \mathrm{g}$ folic acid/100g while maintaining current voluntary fortification and nutritional supplement practices would provide the greatest benefit (increased intake of 148 and $152 \mu \mathrm{g}$ of folic acid daily for WCBA), reducing the risk of occurrence of NTD-affected pregnancies by 32 and 33\%, respectively. For all scenarios examined, exclusion of folic acid from voluntarily fortified foods, nutritional supplements or both would result in smaller reductions in risk of NTD-affected pregnancies highlighting the importance of voluntarily fortified foods and nutritional supplements. It is estimated that current folic acid intake from voluntarily fortified foods and nutritional supplements reduce the risk of NTD-affected pregnancies by about $14 \%$ and $11 \%$, respectively. The potential benefit for NTD reduction of mandatory folic acid fortification of food staples has been shown using similar modelling studies in Ireland and other countries[20,25,28,30,34,35].

The risk of masking anaemia associated with (undiagnosed) vitamin B12 deficiency in older adults would be negligible for all scenarios examined as the probability of exceeding the UL for folic acid, even by a small amount, is very low $(\leq 0.2 \%)$. This conclusion is supported with data from the US where there is no evidence of a higher prevalence of vitamin B12 deficiency 
in the absence of anaemia or macrocytosis among a nationally representative sample of US adults $>50$ years from exposure to higher levels of folic acid in fortified foods after mandatory folic acid fortification[52]. Other possible adverse effects of folic acid fortification of foods have been proposed, including cognitive decline in older adults, cognitive development in children, increased risk of some cancers (e.g. prostate, breast, colorectal), diabetes-related disorders and potential adverse effect of increased circulating unmetabolised folic acid. However, available evidence for these effects is weak and inconsistent and insufficient to establish causal relationships at intakes of folic acid associated with mandatory fortification of foods[25,28-31,24,32,33]. Nevertheless, further research has been recommended to address remaining uncertainties.

Worldwide, the mandatory fortification of food staples with folic acid has been a successful strategy for reducing the prevalence of NTD-affected pregnancies by $16-78 \%$ [14-19]. A recent systematic review and meta-analysis has reported that areas with mandatory folic acid fortification have 30-33\% lower NTD-affected pregnancies than areas with voluntary fortification[53]. Despite this, mandatory legislation enforcing folic acid fortification of the food supply lags behind in some regions and it is estimated that just $15-25 \%$ of the possible folic acid preventable NTD cases are prevented by mandatory folic acid fortification worldwide[53,54]. Within Europe mandatory fortification of bread or flour with folic acid has not yet been implemented in any country but has been recommended in the UK, Ireland, Norway, the Netherlands, Germany and France but not in Italy [28,55,30,56-59]. A common conclusion for all countries was that a continued recommendation for WCBA to consume a daily supplement of $400 \mu \mathrm{g}$ folic acid prior to conception and until the twelfth week of pregnancy would be necessary.

The key strengths of this study are the nationally representative sample included in the NANS and the comprehensive dietary intake and food composition data (including brand level detail) which allowed for the estimation of natural and synthetic folate intakes from fortified foods and nutritional supplements. The food composition database was also updated in 2015 to account for changes in voluntary fortification practices since the time of the survey. Furthermore, this study factored in an overage of $25 \%$ compared to that on the label for voluntarily fortified foods and nutritional supplements to account for additional amounts added by manufacturers to allow for losses during processing and shelf life. Another important strength is the use of statistical modelling to estimate the 'usual intakes' of folate and its derivatives, resulting in a better estimate of the true distribution of usual intakes with shorter 
335 tails at the upper and lower ends therefore improving the estimates of the proportions of the 336 population with intakes above or below a particular reference value (e.g. EAR or UL) which 337 would otherwise be overestimated. Misreporting or under reporting of energy intake, is a 338 known limitation with all dietary assessment; this issue was minimised by a high-level of 339 researcher-participant interaction by trained nutritionists. Potential under reporters were not 340 excluded from this analysis as we found that their exclusion did not increase the proportion of 341 the population exceeding the UL (data not shown).

342 In conclusion, this study has shown that mandatory fortification of bread or flour with folic 343 acid in Ireland would substantially reduce the risk of occurrence of NTD-affected pregnancies 344 while allowing safe consumption of folic acid for older adults at current levels of intake from 345 other foods voluntarily fortified with folic acid and from nutritional supplements. As with any 346 public health programme, this policy would require careful monitoring of the food supply and 347 dietary patterns within the population and should be reviewed on a regular basis for efficacy 348 and safety as new evidence arises. 


\section{References}

1. Pitkin RM (2007) Folate and neural tube defects. The American Journal of Clinical Nutrition 85 (1):285S-288S. doi:10.1093/ajcn/85.1.285S

2. Botto LD, Lisi A, Robert-Gnansia E, Erickson JD, Vollset SE, Mastroiacovo P, Botting B, Cocchi G, de Vigan C, de Walle H, Feijoo M, Irgens LM, McDonnell B, Merlob P, Ritvanen A, Scarano G, Siffel C, Metneki J, Stoll C, Smithells R, Goujard J (2005) International Retrospective Cohort Study Of Neural Tube Defects In Relation To Folic Acid Recommendations: Are The Recommendations Working? BMJ: British Medical Journal 330 (7491):571-573. doi:10.1136/bmj.38336.664352.82

3. MRC Vitamin Study Research Group (1991) Prevention of neural tube defects: Results of the Medical Research Council Vitamin Study. The Lancet 338 (8760):131-137. doi:http://dx.doi.org/10.1016/0140-6736(91)90133-A

4. FSAI (2011) Scientific Recommendations for Healthy Eating Guidelines in Ireland. vol 2. Food Safety Authority of Ireland, Dublin, Ireland

5. Scientific Advisory Committee on Nutrition (2006) Folate and Disease Prevention. London: The Stationery Office

6. CDC (1992) Recommendations for the Use of Folic Acid to Reduce the Number of Cases of Spina Bifida and Other Neural Tube Defects. vol 41(RR-14):1-7. Morbidity and Mortality Weekly Report (MMWR). Washington DC, United States

7. National Health and Medical Research Council NZMoH, Department of Health and Ageing; (2006) Nutrient Reference Values for Australia and New Zealand including Recommended Dietary Intakes Commonwealth of Australia, Canberra (AUST)

8. Sedgh G, Singh S, Hussain R (2014) Intended and Unintended Pregnancies Worldwide in 2012 and Recent Trends. Studies in Family Planning 45 (3):301-314. doi:10.1111/j.17284465.2014.00393.x

9. Tarrant RC, Sheridan-Pereira M , McCarthy RA, Younger KM , Kearney JM (2011) Maternal and Infant Nutritional Supplementation Practices in Ireland: Implications for Clinicians and Policymakers. Irish Medical Journal 104 (6)

10. Bestwick JP, Huttly WJ, Morris JK, Wald NJ (2014) Prevention of Neural Tube Defects: A Cross-Sectional Study of the Uptake of Folic Acid Supplementation in Nearly Half a Million Women. PLoS ONE 9 (2):e89354. doi:10.1371/journal.pone.0089354

11. CDC (2005) Use of Dietary Supplements Containing Folic Acid Among Women of Childbearing Age --- United States, 2005. vol 54(38):955-958. Morbidity and Mortality Weekly Report (MMWR). Washington DC, United States

12. Khodr ZG, Lupo PJ, Agopian AJ, Canfield MA, Case AP, Carmichael SL, Mitchell LE (2014) Preconceptional folic acid-containing supplement use in the national birth defects prevention study. Birth Defects Research Part A: Clinical and Molecular Teratology 100 (6):472-482. doi:10.1002/bdra.23238

13. EUROCAT Folic Acid Working Group. 2009 Prevention of Neural Tube Defects by Periconceptional Folic Acid Supplementation in Europe. http://www.eurocatnetwork.eu/content/Special-Report-NTD-3rdEd-2009.pdf

14. Castillo-Lancellotti C, Tur JA, Uauy R (2012) Impact of folic acid fortification of flour on neural tube defects: a systematic review. Public Health Nutrition 16 (5):901-911. doi:10.1017/S1368980012003576

15. Williams J, Mai CT, Mulinare J, Isenburg J, Flood TJ, Ethen M, Frohnert B, Kirby RS (2015) Updated Estimates of Neural Tube Defects Prevented by Mandatory Folic Acid Fortification - United States, 1995-2011. vol 64(01):1-5. Centers for Disease Control and Prevention, Morbidity and Mortality Weekly Report (MMWR) 
16. De Wals P, Tairou F, Van Allen MI, Uh S-H, Lowry RB, Sibbald B, Evans JA, Van den Hof MC, Zimmer P, Crowley M, Fernandez B, Lee NS, Niyonsenga T (2007) Reduction in Neural-Tube Defects after Folic Acid Fortification in Canada. New England Journal of Medicine 357 (2):135-142. doi:doi:10.1056/NEJMoa067103

17. Barboza-Argüello lMdP, Umaña-Solís LM, Azofeifa A, Valencia D, Flores AL, RodríguezAguilar S, Alfaro-Calvo T, Mulinare J (2015) Neural Tube Defects in Costa Rica, 1987-2012: Origins and Development of Birth Defect Surveillance and Folic Acid Fortification. Maternal and Child Health Journal 19 (3):583-590. doi:10.1007/s10995-014-1542-8

18. De Wals P, Tairou F, Van Allen MI, Lowry RB, Evans JA, Van den Hof MC, Crowley M, Uh S-H, Zimmer P, Sibbald B, Fernandez B, Lee NS, Niyonsenga T (2008) Spina bifida before and after folic acid fortification in Canada. Birth Defects Research Part A: Clinical and Molecular Teratology 82 (9):622-626. doi:10.1002/bdra.20485

19. Liu S, West R, Randell E, Longerich L, O'Connor KS, Scott H, Crowley M, Lam A, Prabhakaran V, McCourt C (2004) A comprehensive evaluation of food fortification with folic acid for the primary prevention of neural tube defects. BMC Pregnancy and Childbirth 4 (1):110. doi:10.1186/1471-2393-4-20

20. National Committee on Folic Acid Food Fortification (2006) Report of the National Committee on Folic Acid Food Fortification. Dublin: Food Safety Authority of Ireland

21. Khoshnood B, Loane M, Walle Hd, Arriola L, Addor M-C, Barisic I, Beres J, Bianchi F, Dias C, Draper E, Garne E, Gatt M, Haeusler M, Klungsoyr K, Latos-Bielenska A, Lynch C, McDonnell B, Nelen V, Neville AJ, O’Mahony MT, Queisser-Luft A, Rankin J, Rissmann A, Ritvanen A, Rounding C, Sipek A, Tucker D, Verellen-Dumoulin C, Wellesley D, Dolk H (2015) Long term trends in prevalence of neural tube defects in Europe: population based study. BMJ 351. doi:10.1136/bmj.h5949

22. Morris MS, Jacques PF, Rosenberg IH, Selhub J (2007) Folate and vitamin B-12 status in relation to anemia, macrocytosis, and cognitive impairment in older Americans in the age of folic acid fortification. The American Journal of Clinical Nutrition 85 (1):193-200. doi:10.1093/ajen/85.1.193

23. Cole BF, Baron JA, Sandler RS, et al. (2007) Folic acid for the prevention of colorectal adenomas: A randomized clinical trial. JAMA 297 (21):2351-2359. doi:10.1001/jama.297.21.2351

24. Bailey LB, Stover PJ, McNulty H, Fenech MF, Gregory JF, Mills JL, Pfeiffer CM, Fazili Z, Zhang M, Ueland PM, Molloy AM, Caudill MA, Shane B, Berry RJ, Bailey RL, Hausman DB, Raghavan R, Raiten DJ (2015) Biomarkers of Nutrition for Development - Folate Review. The Journal of Nutrition. doi:10.3945/jn.114.206599

25. Scientific Advisory Committee on Nutrition (2009) Folic Acid and Colorectal Cancer Risk: Review of Recommendation for Mandatory Folic Acid Fortification. London: The Stationery Office

26. Expert Group on Vitamins and Minerals (EVM) (2003) Safe Upper Levels for Vitamins and Minerals. London, Food Standards Agency

27. European Food Safety Authority (2009) Folic acid: an update on scientific developments. EFSA Supporting Publications 6 (8):2E-n/a. doi:10.2903/sp.efsa.2009.EN-2

28. Scientific Advisory Committee on Nutrition (2017) Update on folic acid. London: The Stationery Office

29. Food and Drug Administration (2016) Food Additives Permitted for Direct Addition to Food for Human Consumption: Folic Acid. vol FDA-2012-F-0489. Department of Health and Human Services, Food and Drug Administration,, Federal Register

30. European Food Safety Authority (2009) ESCO Report on Analysis of Risks and Benefits of Fortification of Food with Folic Acid. EFSA Supporting Publications 6 (8):3E-n/a. doi:10.2903/sp.efsa.2009.EN-3 
31. National Toxicology Program (NTP) (2015) Identifying research needs for safe use of high intakes of folic acid. NTP Monograph. U.S. Department of Health and Human Services 32. VKM (2015) Risk Assessment of Folic Acid in Food Supplements. Scientific opinion

by the Panel on Nutrition, Dietetic Products, Novel Food and Allergy of VKM. European Journal of Nutrition \& Food Safety 5 (4):1-11. doi:10.9734/EJNFS/2015/19619

33. Office of the Prime Minister's Chief Science Advisor and the Royal Society Te Apārangi (2018) The Health Benefits and Risks of Folic Acid Fortification of Food. Auckland, New Zealand

34. Evans SE, Mygind VL, Peddie MC, Miller JC, Houghton LA (2013) Effect of increasing voluntary folic acid food fortification on dietary folate intakes and adequacy of reproductiveage women in New Zealand. Public Health Nutrition 17 (7):1447-1453. doi:10.1017/S1368980013001717

35. Food Standards Australia New Zealand (FSANZ) (2006) Final Assessment Report. Consideration for Mandatory Fortification with Folic Acid.

36. FSAI (2008) Report of the Implementation Group on Folic Acid Food Fortification to the Department of Health and Children. Food Safety Authority of Ireland, Dublin, Ireland

37. Hennessy Á, Hannon EM, Walton J, Flynn A (2015) Impact of voluntary food fortification practices in Ireland: trends in nutrient intakes in Irish adults between 1997-9 and 2008-10. British Journal of Nutrition 113 (02):310-320. doi:doi:10.1017/S0007114514003651

38. Hopkins SM, Gibney MJ, Nugent AP, McNulty H, Molloy AM, Scott JM, Flynn A, Strain J, Ward M, Walton J, McNulty BA (2015) Impact of voluntary fortification and supplement use on dietary intakes and biomarker status of folate and vitamin B-12 in Irish adults. The American Journal of Clinical Nutrition 101 (6):1163-1172. doi:10.3945/ajcn.115.107151

39. McDonnell R, Delany V, O'Mahony MT, Mullaney C, Lee B, Turner MJ (2015) Neural tube defects in the Republic of Ireland in 2009-11. Journal of Public Health 37 (1):57-63. doi:10.1093/pubmed/fdu016

40. McDonnel 1R, Delany V, O'Mahony M, Lynch C, McKeating A, Monteith C, Turner M (2015) An Audit of Neural Tube Defects in the Republic Of Ireland for 2012-2015. Irish Medical Journal 111 (3):712

41. Irish Universities Nutrition Alliance (IUNA) The National Adult Nutrition Survey (NANS). http://www.iuna.net.

42. Cashman KD, Muldowney S, McNulty B, Nugent A, FitzGerald AP, Kiely M, Walton J, Gibney MJ, Flynn A (2013) Vitamin D status of Irish adults: findings from the National Adult Nutrition Survey. British Journal of Nutrition 109 (7):1248-1256. doi:10.1017/S0007114512003212

43. Hayes A, Hennessy Á, Walton J, McNulty BA, Lucey AJ, Kiely M, Flynn A, Cashman KD (2016) Phylloquinone Intakes and Food Sources and Vitamin K Status in a Nationally Representative Sample of Irish Adults. The Journal of Nutrition 146 (11):2274-2280. doi:10.3945/jn.116.239137

44. Central Statistics Office (2007) Census 2006 Principal Demographic Results (trans: Office CS). Dublin: The Stationery Office

45. Black LJ, Ireland J, Møller A, Roe M, Walton J, Flynn A, Finglas PM, Kiely M (2011) Development of an on-line Irish food composition database for nutrients. J Food Compost Anal 24 (7):1017-1023. doi:http://dx.doi.org/10.1016/i.jfca.2011.01.015

46. EFSA Panel on Dietetic Products Nutrition and Allergies (2014) Scientific Opinion on Dietary Reference Values for folate. EFSA Journal 12 (11):3893. doi:10.2903/j.efsa.2014.3893 47. Food Standards Agency (2002) McCance and Widdowson's The Composition of Foods, 6th ed. Cambridge: Royal Society of Chemistry 
48. Tooze JA, Kipnis V, Buckman DW, Carroll RJ, Freedman LS, Guenther PM, Krebs-Smith SM, Subar AF, Dodd KW (2010) A mixed-effects model approach for estimating the distribution of usual intake of nutrients: The NCI method. Statistics in Medicine 29 (27):28572868. doi:10.1002/sim. 4063

49. Daly LE, Kirke PN, Molloy A, Weir DG, Scott JM (1995) Folate levels and neural tube defects: Implications for prevention. JAMA 274 (21):1698-1702. doi:10.1001/jama.1995.03530210052030

50. Daly S, Mills JL, Molloy AM, Conley M, Lee YJ, Kirke PN, Weir DG, Scott JM (1997) Minimum effective dose of folic acid for food fortification to prevent neural-tube defects. The Lancet 350 (9092):1666-1669. doi:http://dx.doi.org/10.1016/S0140-6736(97)07247-4

51. EFSA Panel on Dietetic Products Nutrition and Allergies (2006) Tolerable Upper Intake Levels for Vitamins and Minerals. EFSA Journal

52. Qi YP, Do AN, Hamner HC, Pfeiffer CM, Berry RJ (2014) The Prevalence of Low Serum Vitamin B-12 Status in the Absence of Anemia or Macrocytosis Did Not Increase among Older U.S. Adults after Mandatory Folic Acid Fortification. The Journal of Nutrition 144 (2):170176. doi:10.3945/jn.113.183095

53. Atta CAM, Fiest KM, Frolkis AD, Jette N, Pringsheim T, St Germaine-Smith C, Rajapakse T, Kaplan GG, Metcalfe A (2015) Global Birth Prevalence of Spina Bifida by Folic Acid Fortification Status: A Systematic Review and Meta-Analysis. American Journal of Public Health 106 (1):e24-e34. doi:10.2105/AJPH.2015.302902

54. Youngblood ME, Williamson R, Bell KN, Johnson Q, Kancherla V, Oakley GP (2013) 2012 Update on global prevention of folic acid-preventable spina bifida and anencephaly. Birth Defects Research Part A: Clinical and Molecular Teratology 97 (10):658-663. doi:10.1002/bdra.23166

55. FSAI (2016) Update Rport on Folic Acid and the Prevention of Birth Defects in Ireland. Food Safety Authority of Ireland, Dublin, Ireland

56. Grimstad AL (2007) Folic acid fortification of foods. Estimated intake of folate from different fortification scenarios in Norwegian population groups., University of Oslo,

57. Gezondheidsraad (2008) Naar een optimaal gebruik van foliumzuur (Towards an optimal use of folic acid). Publicatienr. 2008/02. Den Haag.

58. Weissenborn A, Burger M, Mensink GBM, Klemm C, Sichert-Hellert W, Kersting M, Przyrembel H (2005) Folic acid intake of the German population. BfR-Wissenschaft. Berlin. 59. Salerno P, Bianchi F, Pierini A, Baldi F, Carbone P, Mantovani A, Tarusico D (2008) Folic acid and congenital malformation: scientific evidence and public health strategies. Ann Ig 20 (6):519-530 
Table 1. Folic acid modelling scenarios

\begin{tabular}{lccc}
\hline Fortification scenarios & $\begin{array}{c}\text { Mandatory fortification } \\
\text { folic acid } \mu \mathrm{g} / 100 \mathrm{~g} \text { bread/flour }\end{array}$ & Folic acid from voluntary fortification & Folic acid from supplement use \\
\hline Bread120 A & 120 & Included & Included \\
Bread120 B & 120 & Excluded & Included \\
Bread120 C & 120 & Included & Excluded \\
Bread120 D & 120 & Excluded & Excluded \\
& & & Included \\
Bread225 A & 225 & Included & Included \\
Bread225 B & 225 & Excluded & Excluded \\
Bread225 C & 225 & Included & Excluded \\
Bread225 D & 225 & Excluded & \\
Flour225 A & 225 & Included & Included \\
Flour225 B & 225 & Excluded & Included \\
Flour225 C & 225 & Included & Excluded \\
Flour225 D & 225 & Excluded & Excluded \\
\hline
\end{tabular}

With the exception of voluntarily fortified breads.

$0 \quad{ }^{\gamma}$ With the exception of voluntarily fortified flour products. 
Table 2. Distribution of usual dietary intakes of total folate, natural folate, folic acid and dietary folate equivalents in women of child bearing age (WCBA) (18-50y) and older adults ( $>50$ years) from all sources, fortified foods and nutritional supplements at baseline*

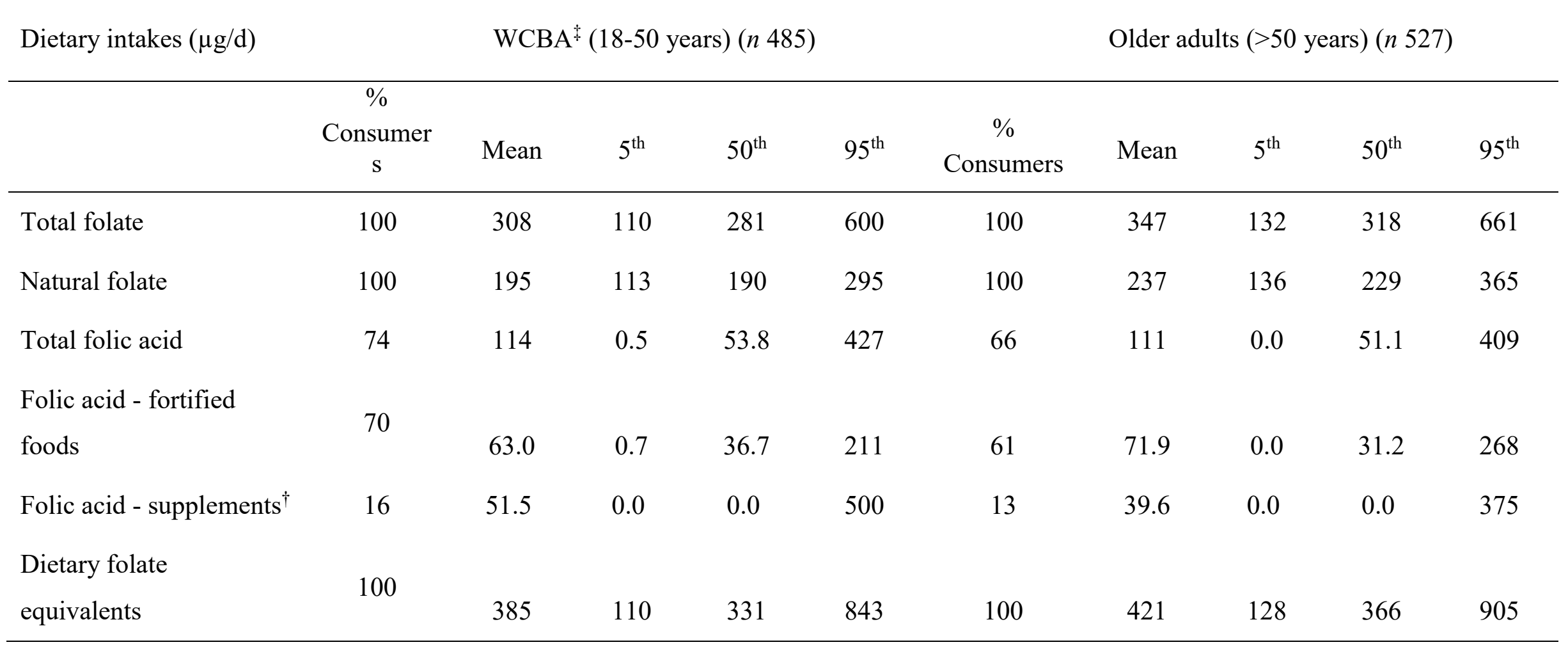

*Baseline data includes $25 \%$ overage for fortified foods and nutritional supplements

WCBA: Women of child bearing age

tUsual intakes of folic acid from supplements could not be calculated via the NCI-method due to the limited number of dietary records with a positive value on more than one recording day; distribution presented from mean daily intakes over the 4 recording days

$\%$ consumers: proportion of the population consuming nutrient at least once in the recording period. 
Table 3. Impact of mandatory fortification of bread or flour on folic acid intakes $(\mu \mathrm{g} / \mathrm{d})$ and reduction (\%) in NTD risk in women of child bearing age (WCBA) ( $n$ 485)

\begin{tabular}{|c|c|c|c|c|}
\hline & Consumers & Mean & Increase & NTD Reduction \\
\hline & $\%$ & $\mu \mathrm{g} / \mathrm{d}$ & $\mu \mathrm{g} / \mathrm{d}$ & $\%$ \\
\hline Baseline* & 74 & 114 & - & - \\
\hline Bread120 A & 96 & 191 & 77 & 17 \\
\hline Bread120 B & 92 & 127 & 13 & 3 \\
\hline Bread120 C & 96 & 141 & 27 & 6 \\
\hline Bread120 D & 90 & 80 & -34 & -7 \\
\hline Bread225 A & 96 & 262 & 148 & 31 \\
\hline Bread225 B & 92 & 200 & 86 & 19 \\
\hline Bread225 C & 96 & 211 & 97 & 21 \\
\hline Bread225 D & 90 & 149 & 35 & 8 \\
\hline Flour225 A & 99 & 266 & 152 & 32 \\
\hline Flour225 B & 99 & 204 & 90 & 20 \\
\hline Flour225 C & 99 & 215 & 101 & 22 \\
\hline Flour225 D & 99 & 153 & 39 & 9 \\
\hline
\end{tabular}

* Baseline data includes $25 \%$ overage for fortified foods and nutritional supplements. A: Including folic acid intake from voluntarily fortified foods and nutritional supplements, B: Effect of exclusion of folic acid from voluntarily fortified foods, C: Effect of exclusion of folic acid from nutritional supplements, D: Effect of exclusion of folic acid from all voluntarily fortified foods and nutritional supplements.

$\%$ consumers: proportion of the population consuming nutrient at least once in the recording period. 
Table 4. Impact of mandatory fortification of bread or flour on folic acid intakes $(\mu \mathrm{g} / \mathrm{d})$ and $\%$ with intakes $>$ UL in older adults $(n$ 527)

\begin{tabular}{|c|c|c|c|c|c|}
\hline \multirow[b]{3}{*}{ Baseline* } & \multirow{2}{*}{$\begin{array}{c}\text { Consumers } \\
\% \\
\end{array}$} & Mean & $95^{\text {th }}$ & $99^{\text {th }}$ & \multirow{2}{*}{$\frac{>\mathrm{UL}}{\%}$} \\
\hline & & \multicolumn{3}{|c|}{$\mu \mathrm{g} / \mathrm{d}$} & \\
\hline & 66 & 111 & 409 & 681 & 0.1 \\
\hline Bread120 A & 97 & 210 & 489 & 695 & 0.1 \\
\hline Bread120 B & 93 & 139 & 342 & 499 & 0.0 \\
\hline Bread120 C & 95 & 171 & 369 & 505 & 0.0 \\
\hline Bread120 D & 92 & 101 & 206 & 263 & 0.0 \\
\hline Bread225 A & 97 & 300 & 623 & 822 & 0.2 \\
\hline Bread225 B & 93 & 229 & 501 & 670 & 0.0 \\
\hline Bread225 C & 95 & 260 & 517 & 667 & 0.0 \\
\hline Bread225 D & 92 & 190 & 386 & 493 & 0.0 \\
\hline Flour225 A & 100 & 289 & 592 & 774 & 0.1 \\
\hline Flour225 B & 99 & 218 & 455 & 594 & 0.0 \\
\hline Flour225 C & 100 & 249 & 477 & 604 & 0.0 \\
\hline Flour225 D & 99 & 179 & 328 & 408 & 0.0 \\
\hline
\end{tabular}

* Baseline data includes $25 \%$ overage for fortified foods and nutritional supplements. A: Including folic acid intake from voluntarily fortified foods and nutritional supplements, B: Effect of exclusion of folic acid from voluntarily fortified foods, C: Effect of exclusion of folic acid from nutritional supplements, D: Effect of exclusion of folic acid from all voluntarily fortified foods and nutritional supplements.

$\%$ consumers: proportion of the population consuming nutrient at least once in the recording period. 
Supplementary Table 1. Folic acid fortified foods ( $n, \%)$ consumed in the National Adult Nutrition Survey

\begin{tabular}{|c|c|c|c|}
\hline Food group & $\begin{array}{l}\text { Number of foods fortified } \\
\text { per group }\end{array}$ & $\begin{array}{l}\text { Total foods in food } \\
\text { group }\end{array}$ & $\begin{array}{l}\% \text { of foods fortified with folic acid } \\
\text { per food group }\end{array}$ \\
\hline \multicolumn{4}{|l|}{ Cereals } \\
\hline Ready-to-eat breakfast cereals & 82 & 101 & 81 \\
\hline Hot oat, museli and granola type cereals & 3 & 65 & 5 \\
\hline Cereal bars & 28 & 65 & 43 \\
\hline Bread and rolls $\ddagger$ & 6 & 326 & 2 \\
\hline \multicolumn{4}{|l|}{ Beverages } \\
\hline Low fat \& skimmed milks & 11 & 67 & 16 \\
\hline Whole milk & 3 & 46 & 7 \\
\hline Fruit juices & 6 & 147 & 4 \\
\hline Other beverages* & 11 & 31 & 35 \\
\hline Packet \& tinned soups & 21 & 95 & 22 \\
\hline Butter $\&$ fat spreads ${ }^{\dot{t}}$ & 5 & 111 & 5 \\
\hline Yoghurts & 7 & 267 & 3 \\
\hline
\end{tabular}

Due to the significant reduction in voluntary folic acid fortification of breads and fat spreads with folic acid since the time of the survey (2008 $2010)$ the 2015 composition is used for these food groups.

* Powdered beverages, beef \& yeast extracts \& food supplements. 